\title{
Primer on Medical History for Anesthesiologists: Introduction
}

\author{
By Manisha S. Desai, MD \\ Department of Anesthesiology \\ University of Massachusetts \\ Worcester, Masschusetts
}

and

Sukumar P Desai, MD

Department of Anesthesiology, Perioperative and Pain Medicine

Brigham and Women's Hospital

Harvard Medical School

Boston, Massachusetts

Editor's note: The absence of a recognized formal curriculum in anesthesia history means that many of us have known and unknown gaps in our knowledge. These gaps limit our ability to understand how things came to be, how things may become and how we can affect the future. I have asked Dr. Manisha Desai and Dr. Sukumar Desai to provide a survey of medical history. The goals of this primer are 1) to educate, and 2) to help individuals target future study. Below is the first article in a continuing series.

As few anesthesia historians and enthusiasts have undergone formal training in history, the primary purpose of this series is to provide a historic perspective about major events that form the basis of modern science, medicine, and anesthesia. We hope these broad horizons help readers better appreciate the human and societal context in which advances in these disciplines occurred.

History of Science: The word 'science' is derived from the Latin scientia which means 'knowledge.' In the past, the term natural philosophy was used for the study of the natural world. From historical records, it is apparent that ancient Western science began with the Babylonians who lived in the first and second millennia BCE in present day Iraq and with the Egyptians. The Babylonians left their writings on clay tablets, and their main contributions were in astronomy and mathematical notation [using a base of 60 , a practice currently followed in the measurement of time in seconds and minutes]. The Egyptians used a solar calendar of 360 days and 5 days of festivals. They introduced metalworking and glassmaking. Thales of Miletus [circa $600 \mathrm{BCE}]$ in Greece is credited with starting the scientific tradition of searching for causes and principles to explain observations made in nature. Thales and other preSocratics concerned themselves with questions related to what the world was made of, how the universe was created, where the world came from, how changes occur, and whether the senses were accurate guides for investigation. Other significant individuals include Anaximander, Anaximenes, Heraclitus, Parmenides, Empedocles, Leucippus, and Democritus. Pythagoras [circa 570-495
$\mathrm{BCE}$ ] established a community rooted in philosophy and mathematics, and he is known for contributions in geometry, irrational numbers, immortality of the soul, and reincarnation. Plato [circa 428-348 BCE], a student of Socrates [circa 469-399 $\mathrm{BCE}$ ], was one of the first to use scientific inquiry by formulating general principles through observing individual objects. In the dialogue Timaeus, Plato describes the origin and structure of the world and its contents. In addition to articulating the characteristics of a harmonious society, the Timaeus also posits the rationale underlying human anatomy and physiology. Pythagoras and Plato believed that the world was created by design, rather than by random events. Plato's student Aristotle [384-322 BCE] still influences ideas about ethics, logic, and biology.

History of Medicine: Paleomedical evidence from between 2,000-10,000 BCE supports the existence of diseases such as tuberculosis, arthritis, and bony abnormalities and treatments such as trephination of the skull, perhaps to remove blood or to let out evil spirits. Imhotep [circa 2900 BCE] in Egypt, and Hippocrates [460-370 BCE] in Greece, are individuals clearly identified with the practice of medicine. Prior to Hippocrates, Aesculapian practices included prayers and rituals, since disease and illness were believed to occur from supernatural causes. Hippocrates, the father of Western medicine, is credited with ascribing natural causes to illness, carrying out careful observation and examination of patients, and keeping accurate records of the progress of illness. These practices allowed Hippocratic physicians to offer diagnosis as well as prognosis. Although Hippocratic physicians believed that body would heal itself, they also believed that they could assist in this process by balancing the four important body fluids-blood [energy], yellow bile [anger], black bile [depression], and phlegm [slow temperament]. They also treated fractures and drained abscesses and hematomas. Hippocrates is best remembered for his strict moral code of the Hippocratic Oath.

History of Anesthesia: Man has sought relief from the cardinal symptom of pain since times immemorial. Introduction of nitrous oxide and ether in the middle of the 19 th century greatly accelerated the development of surgery, but prior to the mid-1840s, painful procedures were still necessary, and the role of anesthetic agent was served by substances known to be analgesics, sedatives, amnesiacs, or hallucinogens. Agents most often quoted in the literature are alcohol, opium, cannabinoids, and the belladonna derivatives.

Alcohol: Winemaking traces its origins to those of agriculture, civilization, and society. The fermentation process has been applied as early as 9000 BCE in Georgia and $5000 \mathrm{BCE}$ in regions surrounding the Mesopotamian basin. Its use was known in ancient Greece and Egypt. Grape juice was used in most of these regions, but in the Middle East honey and dates were substituted. The use of alcohol fumes as an anesthetic was recorded in the mid-16th century. Surgeons would occasionally intoxicate patients with alcohol in the 18th and 19th century, especially when the 'procedure necessitated freedom from struggling.' In 1842, a painless dental extraction was reported under alcohol anesthesia. Although alcohol 
was administered intravenously in as early as 1668 , there was no mention of its use as an analgesic. With the availability of modern agents, intravenous alcohol anesthesia has been used rarely during the past century.

Opium: The poppy Papaver somniferum (Figure 1) has been cultivated at least since the Neolithic Age [10,000 BCE]. Inhabitants in the Middle East, India, Egypt, as well as those in the Greek and Roman empires were aware of the analgesic effects of opium. The term opium refers to the dried milky extract

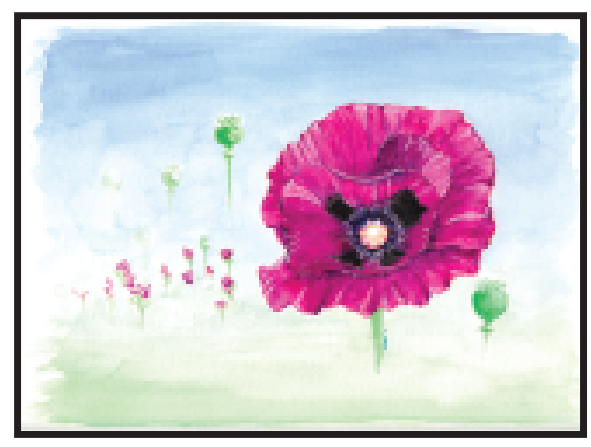

Fig. 1. Papaver somniferum. Wood LibraryMuseum of Anesthesiology, Park Ridge, IL. Reproduced with permission.

of the fruit of this plant. It contains several alkaloids [naturally occurring compounds with basic nitrogen groups], mainly morphine [ $12 \%$ by weight], as well as smaller amounts of codeine, papaverine [a smooth muscle relaxant and vasodilator], thebaine [a stimulant chemically related to morphine that can also be used to manufacture other narcotics such as oxycodone, oxymorphone, nalbuphine, naloxone, naltrexone, and buprenorphine], and noscapine [a nonanalgesic cough suppressant]. Dried opium was used by itself or, more commonly, as a mixture with other plant ingredients to offer relief for a wide variety of disorders.

Cannabinoids: The active ingredient tetrahydrocannabinol [THC] is just one of several dozen cannabinoid compounds that can be harvested from several plant species [Cannabis sativa, Cannabis indica, among others] and these plant derivatives have been called hemp, hashish, ganja, marijuana, etc. THC stimulates cannabinoid receptors in the central nervous system. TCH provides mild to moderate analgesia, suppresses nausea, increases appetite, reduces fatigue, alters visual and auditory sensations, and promotes a sense of relaxation. As with opium, the preparation could be used alone or combined with other ingredients.

Belladonna Derivatives: These ingredients are obtained from the deadly nightshade plant Atropa belladonna (Figure 2). The active ingredients in the plant extract include atropine, hyoscine [scopolamine], and hyoscamine. Other names used for plants or extracts that contain these and other similar compounds include henbane, mandrake, and mandragora. Preparations that contain belladonna derivatives provided relief during surgery by delirium, hallucinations, and amnesia. These drugs have also long been used as poisons, and the term belladonna ("beautiful lady") is derived from Italian, as Venetian ladies used these herbs to dilate their pupils and appear attractive.

Soporific Sponges: These were used as vehicles for delivering vapors during surgery. Sea sponges were soaked in a variety of potions containing alcohol, opium, belladonna alkaloids, and even poisons such as hemlock [which contains many toxins including the neurotoxin coniine]. After absorbing these potions, the sponge was dried out. The sponge would be moistened with warm water and placed near the nose before and during the surgical procedure.

Mesmerism: Franz Mesmer introduced Mesmerism in Vienna in 1775 . He had a fanatical following in Europe, and the technique was used to cure a variety of illnesses and to relieve pain during surgery. It was not always effective as an anesthetic, although it was used widely in Europe as well as the colonies in Asia. It was largely abandoned after a French committee that included Benjamin Franklin amongst its members determined that the technique was a fraud.

Other Methods: Bleeding, nerve compression, bilateral carotid artery compression, and exposure of the skin to be incised to various chemicals were other techniques used to obtain relief from surgical pain.

Summary: Man's ingenuity in obtaining pain relief allowed many patients to be rendered unaware during surgical procedures. It is likely that many patients succumbed to overdose of these potent agents and toxins. However, it is also possible that combining drugs with different mechanisms of action allowed practitioners a margin of safety not possible with the use of only one drug. This might represent the earliest use of balanced

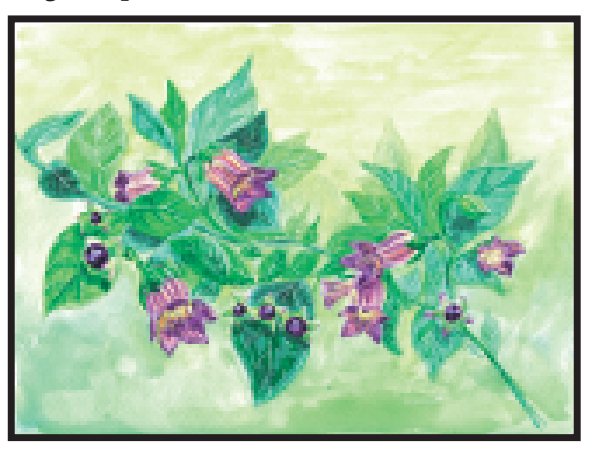

Fig. 2. Atropa belladonna. Wood LibraryMuseum of Anesthesiology, Park Ridge, IL. Reproduced with permission. anesthesia.

Next: We shall discuss other advances made in science during the classical period, the role of Galen and how his work influenced medical thinking for almost a millennium, and the period of the 1840s during which our specialty was born.

\section{Additional Reading}

1. Lindberg DC. The Beginnings of Western Science, 2nd Edition. Chicago: University of Chicago Press; 2007.

2. Singer C, Underwood EA. A Short History of Medicine, 2nd Edition. Oxford: Oxford University Press; 1962

3. Chadwick J, Mann WN. The Medical Works of Hippocrates. Oxford: Blackwell Scientific Publications; 1950.

4. Keys TE. The History of Surgical Anesthesia. Park Ridge, Illinois: Wood Library-Museum of Anesthesiology; 1996. 